\title{
Extended erythrocyte and reticulocyte parameters in the diagnosis of iron deficiency in hemodialysis patients
}

\author{
Mohammed Nazim Bennaoum ${ }^{1,2^{*}}$, Affaf Adda ${ }^{1,2}$, Mohamed Chekkal ${ }^{1,2}$, Fatima Seghier ${ }^{2,3}$ \\ 1 Department of Hemobiology EHU "1er Novembre 1954" Oran, Algeria. \\ 2 University of Oran 1 Ahmed Ben Bella Faculty of Medicine. \\ 3 Department of Hemobiology CHU Oran, Algeria. \\ *Corresponding Author: Mohammed Nazim Bennaoum, Department of Hemobiology EHU "1er Novembre 1954 " BP N 4166 Ibn \\ E-mail: benazim@ymail.com, Tel: +213553276733
} Rochd Oran, Algéria

\section{Abstract}

Objective: Iron deficiency (ID) is a frequent complication in end stage renal insufficiency. These patients have to be diagnosed and treated to reduce the prevalence of anemia. Functional iron deficiency (FID) is a situation that can disrupt biochemical iron tests and mask an eventual association with ID. In this study, we tried to prove the ability of extended parameters of red cells and reticulocytes to diagnose ID without being influenced by FID. Design and methods: 164 chronic hemodialysis patients (CHP) in end stage renal disease were enrolled. Research parameters of red cells and reticulocytes determined on ADVIA 2120i were studied in the diagnosis of ID associated or not with chronic inflammation. Results: Parameters such as corpuscular hemoglobin of mature red cells $(\mathrm{CHm})$, corpuscular hemoglobin of reticulocytes (CHr), cellular concentration of hemoglobin in mature red cells $(\mathrm{CHCMm})$, cellular concentration of hemoglobin in reticulocytes $(\mathrm{CHCMr})$ and percentage of microcytic and hypochromic red cells (HYMI) showed a high sensitivity to diagnose ID. However, the distinction of combined iron deficiency (CID) from other entities was not possible with all parameters. In chronic inflammatory states, the decrease of $\mathrm{CHm}, \mathrm{CHCMm}$ and $\mathrm{CHCMr}$ with the rise of percentage hypochromic mature red cells (HYPOm) and reticulocytes (HYPOr) is in favor of CID. So, determination of inflammatory state is needed to complete research parameters of blood count in CHP. Conclusion: Extended erythrocyte and reticulocyte parameters can be useful to check iron status in CHP.

Keywords: Hematology analyzer, hemodialysis, iron deficiency anemia.

\section{INTRODUCTION}

Anemia is the most serious complication in CHP. It is found in $70 \%$ of these patients and is responsible of important degradation of quality of life ${ }^{[1-3]}$. In end stage renal insufficiency, anemia is a consequence of accumulation of toxic metabolites, ID, FID and reduced erythropoietin production by renal failure, this situation is also observed in patients with a glomerular filtration rate less than $40 \mathrm{~mL} / \mathrm{min} / 1.73 \mathrm{~m}^{2}[4,5]$.

Iron is the most important element for the development and the growth of the majority of living organisms. It plays a role in the transport of oxygen, synthesis of ATP and ADP and regulation of the cell cycle ${ }^{[1]}$.

ID is accentuated by chronic blood loss in hemodialysis patients and is found in about $47 \%$ of them ${ }^{[1,2]}$. In this case, iron stores and iron absorbed by enterocytes are insufficient to maintain a normal erythropoiesis. Patients with ID have to be treated by oral or parenteral iron administration for more efficiency.

FID is a particular situation where iron is not available for erythropoiesis despite normal or important stores secondary to reduced iron carriers [6]. FID is present in about $50 \%$ of CHP, it is considered as a complication of inflammatory states and the use of erythropoiesis stimulating agents ${ }^{[3,7]}$. In this situation, biochemical parameters (serum iron, total iron binding capacity and serum ferritin) are unable to be used in the determination of iron status ${ }^{[2,7]}$. A great interest was made to develop biological parameters permitting determination of iron status without being influenced by inflammatory state.

Many studies have shown the interest of $\mathrm{CHr}$ and HYPOm in the exploration of iron metabolism and erythropoiesis. Actually, many other parameters are provided by recent hematology analyzers described as research parameters of red cells and reticulocytes. So in this work, we tried to demonstrate the 
interest of these research parameters in determination of iron status in CHP.

\section{MATERIAL AND METHODS}

This prospective study was performed in the department of hemobiology of the 1st November hospital of Oran. Overall 164 chronic hemodialysis patients were enrolled from two hemodialysis center. All patients were in end stage renal disease and are treated by hemodialysis for more than one year. Has been excluded all patients recently transfused or receiving iron therapy. Patients were orally informed about the purpose of this study and approved their consent.

Complete blood count was realized on ADVIA 2120i (Siemens Healthcare). Serum ferritin and $C$ reactive protein (CRP) were performed by immunoturbidimetric latex essay (BioSystems).

Patients with anemia received intravenous iron therapy and hemoglobin rate was controlled after one month. Patients with a rise of hemoglobin greater than $10 \mathrm{gr} / \mathrm{l}$ were considered as having an ID as recommended by Hershko [9]. According to the inflammatory status, patients were classified in 4 groups: ID, FID, CID and normal.

Volumetric parameters studied were the mean corpuscular volume of mature erythrocytes and reticulocytes (MCVm and $\mathrm{MCVr}$ respectively), the report $\mathrm{MCVr} / \mathrm{MCVm}$, the red cell factor
(RCf) calculated by the equation $R C f=\sqrt{(\mathrm{MCVm} \times \mathrm{MCVr})}$ [10] and percentage of microcytic red cells and microcytic reticulocytes (MICROm and MICROr respectively).

Parameters of hemoglobin studied were $\mathrm{CHm}, \mathrm{CHCMm}, \mathrm{CHr}$, $\mathrm{CHCMr}$, the report $\mathrm{CHr} / \mathrm{CHm}$, HYPOm, HYPOr and HYMI.

The immature reticulocyte fraction (FRI) was also included in the study.

\section{Statistical analysis}

Collected data was analyzed with SPSS 20 (IBM statistics). ROC curves were established for all parameters in the screening of ID and completed with the determination of sensitivity and specificity. Student t test for mean comparison of all parameters was used to search statistical difference between ID, FID, CID and normal.

Statistical significance was defined as $\mathrm{P}<0.05$

\section{RESULTS}

Anemia was present in about $83 \%$ of $\mathrm{CHP}$ and ID was confirmed in $14 \%$. Concerning inflammatory status, CRP was elevated in $23 \%$ of patients so we concluded that $5.7 \%$ of patients had CID. In table 1 our data are compared with other studies, the frequency of ID is less important in our series.

Table 1: Prevalence of anemia, ID and FID in hemodialysis patients. A comparison between studies (ND: not determined).

\begin{tabular}{|l|l|l|l|}
\hline Study & Anemia & ID & FID \\
\hline Our results & $82.9 \%$ & $14.3 \%$ & $23.3 \%$ \\
\hline Benmansour ${ }^{[3]}$ & $89.7 \%$ & $39.7 \%$ & $51 \%$ \\
\hline Barde $^{[2]}$ & $77.3 \%$ & $25.33 \%$ & ND \\
\hline KDOQI $^{[1]]}$ & ND & $25-38 \%$ & ND \\
\hline Biniaz ${ }^{[12]}$ & ND & ND & $41.3 \%$ \\
\hline Valderrabans $^{[13]}$ & ND & $39 \%$ & $21 \%$ \\
\hline
\end{tabular}

ROC curve and analysis of area under curve are summarized in table 2. Cutoff, sensitivity and specificity were calculated only for parameters presenting an area under curve upper than 0.7 .

Table 2: Results of ROC curve analysis of all parameters in the diagnosis of ID.

\begin{tabular}{|l|l|l|l|l|}
\hline Parameter & Area under curve & Cutoff & Sensitivity & Specificity \\
\hline $\mathrm{CHm}$ & 0.909 & $26.4 \mathrm{pg}$ & $100 \%$ & $70 \%$ \\
\hline $\mathrm{CHr}$ & 0.888 & $27.5 \mathrm{pg}$ & $100 \%$ & $75 \%$ \\
\hline $\mathrm{CHCMm}$ & 0.823 & $31.7 \mathrm{~g} / \mathrm{dl}$ & $85.70 \%$ & $85 \%$ \\
\hline $\mathrm{CHCMr}$ & 0.909 & $26.9 \mathrm{~g} / \mathrm{dl}$ & $71.40 \%$ & $95 \%$ \\
\hline ferritin & 0.754 & $478 \mu \mathrm{g} / \mathrm{l}$ & $100 \%$ & $42.50 \%$ \\
\hline RCf & 0.707 & $90.3 \mathrm{fl}$ & $85.70 \%$ & $55 \%$ \\
\hline MICROm & 0.722 & $0.95 \%$ & $93.30 \%$ & $38.60 \%$ \\
\hline HYPOm & 0.776 & $6.45 \%$ & $93 \%$ & $34.10 \%$ \\
\hline HYPOr & 0.755 & $59.70 \%$ & $86.70 \%$ & $58 \%$ \\
\hline HYMI & 0.821 & $0.15 \%$ & $80 \%$ & $72.70 \%$ \\
\hline MICROr & 0.597 & $\mathrm{ND}$ & $\mathrm{ND}$ & $\mathrm{ND}$ \\
\hline MCVm & 0.695 & $\mathrm{ND}$ & $\mathrm{ND}$ & $\mathrm{ND}$ \\
\hline
\end{tabular}




\begin{tabular}{|l|l|l|l|l|}
\hline MCVr & 0.663 & ND & ND & ND \\
\hline CH ratio & 0.554 & ND & ND & ND \\
\hline MCV ratio & 0.661 & ND & ND & ND \\
\hline IRF & 0.555 & ND & ND & ND \\
\hline
\end{tabular}

Cutoff, sensitivity and specificity were calculated just for parameters with an area under curve upper than 0.7 .

Comparisons between groups are summarized in table 3. We identified parameters with statistical difference between all situations; ID was clearly identified by many parameters but CID was more difficult to be distinguished.

Table 3: A comparison of different cutoffs of $\mathrm{CHr}$ and HYPO determined by some authors and confronted to our results.

\begin{tabular}{|c|c|c|}
\hline Study & $\mathrm{CHr}$ & HYPO \\
\hline Our cutoffs & $27.5 \mathrm{pg}$ & $6.45 \%$ \\
\hline Locatelli ${ }^{[14]}$ & $29 \mathrm{pg}$ & $10 \%$ \\
\hline${ }^{\text {Urrechaga }(2016)^{[15]}}$ & $30.8 \mathrm{pg}$ & $2.4 \%$ \\
\hline Urrechaga (2012) ${ }^{16]}$ & ND & $3.6 \%$ \\
\hline $\mathrm{KDOQ}^{[11]}$ & $29 \mathrm{pg}$ & ND \\
\hline Karlsson ${ }^{[17]}$ & $30.5 \mathrm{pg}$ & ND \\
\hline Vidyadhar ${ }^{[18]}$ & ND & $2.45 \%$ \\
\hline Buttarello ${ }^{[19]}$ & $31.2 \mathrm{pg}$ & $5.8 \%$ \\
\hline Luo ${ }^{[20]}$ & ND & $1.55 \%$ \\
\hline Agarwal ${ }^{[21]}$ & $25 \mathrm{pg}$ & ND \\
\hline Thomas ${ }^{[8]}$ & $28 \mathrm{pg}$ & ND \\
\hline Mitsuiki ${ }^{[22]}$ & $32 \mathrm{pg}$ & ND \\
\hline Igartua ${ }^{[23]}$ & $30 \mathrm{pg}$ & ND \\
\hline Lorenz ${ }^{[24]}$ & $29 \mathrm{pg}$ & ND \\
\hline Chinudomwong ${ }^{[25]}$ & $30 \mathrm{pg}$ & ND \\
\hline
\end{tabular}

Table 4: Means and references intervals of all parameters in different situations.

\begin{tabular}{|c|c|c|c|c|c|}
\hline Parameters & ID mean & FID mean & CID mean & Normal mean & Signification \\
\hline MCVm (fl) & $83.98(71.7-96.2)$ & $85.96(72.9-101.2)$ & $82.50(69.2-94.8)$ & $86.67(77.3-97.2)$ & - \\
\hline $\operatorname{MCVr}(\mathrm{fl})$ & $103.93(90.8-114.6)$ & $103.83(88.1-121.9)$ & $100.55(93.6-113.2)$ & $103.6(93.3-116.4)$ & - \\
\hline $\mathrm{CHm}(\mathrm{pg})$ & $25.82(22.4-29.9)$ & $27.51(23.6-31)$ & $25.17(20.9-29.7)$ & $28.25(25.1-31.4)$ & 1,4 \\
\hline $\mathrm{CHr}(\mathrm{pg})$ & $27.48(24.3-30.4)$ & $28.98(23.1-33.6)$ & $26.38(24.2-30.9)$ & $29.54(26.1-33)$ & 3,6 \\
\hline CHCMm (g/dl) & $31.01(29.1-33.4)$ & $32.24(29.2-34.8)$ & $30.65(29.5-31.7)$ & $32.35(29.6-35.4)$ & $1,3,4,6$ \\
\hline $\mathrm{CHCMr}(\mathrm{g} / \mathrm{dl})$ & $26.6025-28.5)$ & $28.02(26.3-31)$ & $26.28(25.1-27.7)$ & $28.70(25.4-31.9)$ & $1,3,4,6$ \\
\hline MICROm (\%) & $3.93(0.2-10.4)$ & $2.42(0.2-12)$ & $6.08(1.1-24.9)$ & $1.61(0.2-4.4)$ & 3 \\
\hline MICROr (\%) & $0.29(0-1.1)$ & $0.33(0-2.4)$ & $0.38(0-0.7)$ & $0.37(0-1)$ & \\
\hline HYPOm (\%) & $16.13(6.7-33.7)$ & $6.96(0.8-27.9)$ & $18.15(9.4-25.8)$ & $6.56(0.2-26.1)$ & $1,3,4,6$ \\
\hline HYPOr (\%) & $72.47(47.5-92)$ & $52.91(11.9-79.7)$ & $71.70(59.8-87.9)$ & $42.15(7.6-83.5)$ & $1,3,4,6$ \\
\hline Ferritin $(\mu \mathrm{g} / \mathrm{l})$ & $224.37(3.8-120)$ & $437.71(83.6-795)$ & $233.85(14.1-464.2)$ & $335.49(72-718.8)$ & 1,3 \\
\hline HYMI (\%) & $0.47(0.1-0.9)$ & $0.20(0-1.2)$ & $0.92(0.1-4.1)$ & $0.08(0-0.4)$ & 1,3 \\
\hline RCf (fl) & $91.8(79.7-102.1)$ & $92.71(82.02-105.5)$ & $88.29(80.4-97.2)$ & $93.77(84.69-104.4)$ & 6 \\
\hline MCV ratio & $1.24(1.18-1.28)$ & $1.21(1.07-1.31)$ & $1.22(1.13-1.38)$ & $1.20(1.15-1.25)$ & 3 \\
\hline $\mathrm{CH}$ ratio & $1.07(1.02-1.11)$ & $1.05(0.9-1.19)$ & $1.05(0.96-1.16)$ & $1.06(1.02-1.1)$ & - \\
\hline IRF (\%) & $24.85(1.42-55.02)$ & $25.15(2.01-52.6)$ & $34.57(9.38-54.61)$ & $23.28(2.97-49.6)$ & - \\
\hline
\end{tabular}

Statistical differences between groups are noticed: 1: ID vs FID, 2: ID vs CID, 3: ID vs controls, 4: FID vs CID, 5: FID vs controls, 6: CID vs controls. 


\section{DISCUSSION}

Many studies evaluated the interest of red cell and reticulocyte parameters in erythropoiesis disorders especially ID even before the development of anemia [27-31]. In this work, we tried to demonstrate the interest of some cellular parameters determined by novel hematology analyzer in the diagnosis of ID in hemodialysis patients with or without FID. End stage renal insufficiency patients present a high frequency of anemia, ID and inflammation so the discrimination of these situations is essential for the follow-up. Frequencies of anemia and FID were close to results of other studies. However, ID was less frequent. Probably it was necessary to stop iron therapy for more than three months.

Research parameters of red cells and reticulocytes are considered as reflecting erythropoiesis activity in relation with iron supply to erythroid precursors. Red cells become smaller and contain less hemoglobin as they age, a reduction in the rate of red cells turnover allows smaller and hypochromic cells to continue circulating to extend their lifespan [32].

Many studies have demonstrated the interest of $\mathrm{CHr}$ and HYPO in the diagnosis of ID while other cellular parameters were little studied.

Serum ferritin is widely used in routine determination of iron status $[33,34]$ and we also found a significant efficiency to diagnose ID. However, being an acute phase protein, serum ferritin rate tends to be increased in inflammatory states so in our study, serum ferritin was unable to distinguish CID from other groups.

The rise of hemoglobin rate after intravenous iron therapy was used as gold standard to diagnose ID as recommended by Hershko [9]. Thus, the most significant parameters in the diagnosis of ID were $\mathrm{CHm}, \mathrm{CHr}, \mathrm{CHCMm}, \mathrm{CHCMr}$ and $\mathrm{HYMI}$. In contrast with many authors, HYPO was less significant as well as for RCf, MICRO. Parameters reflecting hemoglobin content seem to be more interesting in determination of iron status than parameters in relation with size of cells.

Different cutoffs of ID were assigned for $\mathrm{CHr}$ and HYPO and there is a great variability between authors. These variations can be explained by the interlaboratory heterogeneity and the need of more standardization of analyzers. The technical differences and calculation algorithms used in different analyzers can explain these different cutoffs values reported ${ }^{[35]}$. Actually, the usefulness of cellular parameters is widely proved but each laboratory has to set its own normal values and cutoffs.

In end stage renal insufficiency patients, cellular parameters were able to diagnose patients with ID and distinguish them from FID especially $\mathrm{CHm}$, CHCMm, CHCMr, HYPOm, HYPOr, HYMI. However, any test could separate patients with CID from FID and ID, so it is important to complete cellular analysis with inflammatory tests as recommended by Vidiyadhar [19].

According to these results, an algorithm can be developed. Negative CRP excludes FID and CID and patients have to be classed as normal or ID. For this, parameters such as $\mathrm{CHr}$, $\mathrm{CHCMm}$, CHCMr, MICROm, HYPOm, HYPOr and HYMI can be used or only serum ferritin. When CRP is increased it's important to differentiate between FID and CID. The decrease of $\mathrm{CHm}$, $\mathrm{CHCMm}$ and $\mathrm{CHCMr}$ with the rise of HYPOm and HYPOr is in favor of CID.
CONCLUSION

Simple and quickly available, extended erythrocyte and reticulocyte parameters seem to be useful for checking iron status in CHP. However, determination of inflammatory state is needed.

\section{Conflict of interest}

None to disclose.

\section{Authors' contributions}

All authors have approved the final article. MN BENNAOUM wrote the manuscript with support from the remaining authors.

\section{REFERENCES}

1. Hsu C-Y, McCulloch CE, Curhan GC. Epidemiology of anemia associated with chronic renal insufficiency among adults in the United States: results from the Third National Health and Nutrition Examination Survey. Journal of the American Society of Nephrology, 2002; 13(2):504-510.

2. Barde R, Patel HV, Shah PR. A study of anemia prevalence in CKD patients on maintenance hemodialysis: A single centre study. Journal of Evidence Based Medicine and Healthcare, 2015; 2(39):6344-48.

3. Benmansour N. Place du recepteur soluble de la transferrine dans le diagnostic et le traitement de la carence martiale chez l'insuffisant renal chronique. thése desm 2012 [cited 2015 april]; available from: http://dspace.univ-tlemcen.dz/bitstream/ 112/6802/1/place-du-recepteur-soluble-de-la-transferrine-dansle-diagnostic-et-le-traitement-de-la-carence-martiale-chezlinsuffisant-renal-chronique.pdf.

4. Lankhorst CE, Wish JB. Anemia in renal disease: diagnosis and management. Blood Rev, 2010; 24(1):39-47.

5. Kumar L, Chellapuram SK, Dev R, Varshneya A, Pawar S, Sharma A, et al. Induction Therapy with Novel Agents and Autologous Stem Cell Transplant Overcomes the Adverse Impact of Renal Impairment in Multiple Myeloma. Clinical Hematology International. 2019; 1(4):205-19.

6. Weiss G, Goodnough LT. Anemia of chronic disease. N Engl J Med, 2005; 352(10):1011-23.

7. Thomas DW, Hinchliffe RF, Briggs C, Macdougall IC, Littlewood $\mathrm{T}$, Cavill I et al. Guideline for the laboratory diagnosis of functional iron deficiency. Br J Haematol, 2013; 161(5):639-648.

8. Thomas C, Thomas L. Biochemical markers and hematologic indices in the diagnosis of functional iron deficiency. Clin Chem, 2002; 48(7):1066-1076.

9. Hershko C, Camaschella C. How I treat unexplained refractory iron deficiency anemia. Blood, 2014; 123(3):326-333.

10. Urrechaga E. Clinical utility of the new Beckman-Coulter parameter red blood cell size factor in the study of erithropoiesis. Int J Lab Hematol, 2009; 31(6):623-9.

11. National KF. KDOQI clinical practice guidelines and clinical practice recommendations for anemia in chronic kidney disease. American journal of kidney diseases: the official journal of the National Kidney Foundation, 2006; 47(5 Suppl 3):S11.

12. Biniaz V, Tayebi A, Shermeh MS, Abbas E, Nemati E. Prevalence of Functional Iron Deficiency (FID) Anemia in Patients Undergoing Hemodialysis. Iran J Crit Care Nurs, 2014; 7(1):59-66.

13. Valderrábano F, Hörl WH, Macdougall IC, Rossert J, Rutkowski B, Wauters JP. PRE-dialysis survey on anaemia management. Nephrology Dialysis Transplantation, 2003; 18(1):89-100.

14. Locatelli F, Aljama P, Barany P, Canaud B, Carrera F, Eckardt K et al. Revised European best practice guidelines for the management of anaemia in patients with chronic renal failure. Nephrology, dialysis, transplantation: official publication of the European Dialysis and Transplant Association-European Renal Association, 2004; 19:ii1.

15. Urrechaga E, Boveda O, Aguayo F, De la Hera P, Munoz R, Gallardo I et al. Percentage of hypochromic erythrocytes and reticulocyte hemoglobin equivalent predictors of response to intravenous iron in hemodialysis patients. Int J Lab Hematol, 2016; 38(4):360-365. 
16. Urrechaga E, L Borque, Escanero JF. Biomarkers of hypochromia: the contemporary assessment of iron status and erythropoiesis. Biomed Res Int, 2013; p. 603786.

17. Urrechaga E, Borque L, Escanero JF. Percentage of hypochromic erythrocytes as a potential marker of iron availability. Clin Chem Lab Med, 2012; 50(4):685-687.

18. Karlsson T. Comparative evaluation of the reticulocyte hemoglobin content assay when screening for iron deficiency in elderly anemic patients. Anemia, 2011. 2011.

19. Vidyadhar R. Evaluation of Anaemia using red cell and Reticulocyte Parameters using Automated Haematology Analyser. Journal of Evidence Based Medicine and Healthcare, 2016; 3(10):18410.

20. Buttarello M, Pajola R, Novello E, Rebeschini M, Cantaro S, Oliosi $\mathrm{F}$ et al. Diagnosis of iron deficiency in patients undergoing hemodialysis. Am J Clin Pathol, 2010; 133(6):949-54.

21. Luo D, Ma H, Lin J, Quan S, Feng J, Ren Q et al. Percentage of hypochromic red cells: a better predictive marker than conventional hematological parameters in the diagnosis of latent iron deficiency in women with menometrorrhagia. Int J Clin Exp Med, 2016; 9(5):8593-8598.

22. Agarwal M, Pai S. Reticulocyte Hemoglobin Content $(\mathrm{CHr})$ : The Gold Standard for Diagnosing Iron Deficiency. Journal of The Association of Physicians of India, 2017; 65:11.

23. Mitsuiki K, Harada A, Miyata Y. Reticulocyte hemoglobin content in hemodialysis patients with acute infection. Journal of Clinical and Experimental Nephrology, 2004; 8(3):257-262.

24. Igartua EU, Hoffmann JJ, Izquierdo-Álvarez S, Escanero JF. Reticulocyte hemoglobin content $(\mathrm{MCHr})$ in the detection of iron deficiency. Journal of Trace Elements in Medicine and Biology, 2017; 43:29-32.

25. Lorenz L, Arand J, Büchner K, Wacker-Gussmann A, Peter A Poets CF et al. Reticulocyte haemoglobin content as a marker of iron deficiency. Archives of Disease in Childhood-Fetal and Neonatal Edition, 2015; 100(3):F198-F202.

26. Chinudomwong $\mathrm{P}$, Binyasing $\mathrm{A}$, Trongsakul $\mathrm{R}$, Paisooksantivatana K. Diagnostic performance of reticulocyte hemoglobin equivalent in assessing the iron status. J Clin Lab Anal, 2020: p. e23225.

27. Brugnara C, Schiller B, Moran J. Reticulocyte hemoglobin equivalent (Ret $\mathrm{He})$ and assessment of iron-deficient states. Clinical \& Laboratory Haematology, 2006; 28(5):303-308.

28. Theurl I, Aigner E, Theurl M, Nairz M, Seifert M, Schroll A et al. Regulation of iron homeostasis in anemia of chronic disease and iron deficiency anemia: diagnostic and therapeutic implications. Blood, 2009; 113(21):5277-5286.

29. Fishbane S. Shapiro W, Dutka P, Valenzuela OF, Faubert J. A randomized trial of iron deficiency testing strategies in hemodialysis patients. Kidney Int, 2001; 60(6):2406-2411.

30. Warady BA. Kausz A, Lerner G, Brewer ED, Chadha V, Brugnara $\mathrm{C}$ et al. Iron therapy in the pediatric hemodialysis population. Pediatric Nephrology, 2004; 19(6): 655-661.

31. Brugnara C. Reticulocyte cellular indices: a new approach in the diagnosis of anemias and monitoring of erythropoietic function. Critical reviews in clinical laboratory sciences, 2000; 37(2):93-130.

32. Patel HH, Patel HR, Higgins JM. Modulation of red blood cell population dynamics is a fundamental homeostatic response to disease. Am J Hematol, 2015; 90(5):422-428.

33. Organization WH. Assessing the iron status of populations: report of a Joint World Health Organization/Centers for Disease Control and Prevention Technical Consultation on the Assessment of Iron Status at the Population Level, Geneva, Switzerland, 6-8 April 2004, in Assessing the iron status of populations: report of a Joint World Health Organization/Centers for Disease Control and Prevention Technical Consultation on the Assessment of Iron Status at the Population Level, Geneva, Switzerland, 6-8 April 2004, 2005.

34. Thomas $\mathrm{L}$, Thomas $\mathrm{C}$. Detection of iron restriction in anaemic and non-anaemic patients: New diagnostic approaches. Eur J Haematol, 2017; 99(3):262-268.

35. Urrechaga E. Discriminant value of\% microcytic cells $/ \%$ hypochromic cells ratio in the differential diagnosis of microcytic anemia. Thalassemia Reports, 2020; 10(1). 